\title{
Phenomenological Consideration on the Change from the Non-thermoelastic to the Thermoelastic Type of Martensitic Transformations in $\mathrm{Fe}_{3} \mathrm{Pt}$ Alloy*
}

\author{
By Tsugio Tadaki**
}

\begin{abstract}
Phenomenological calculations have been carried out on the crystallographies of nonthermoelastic and thermoelastic martensitic transformations in $\mathrm{Fe}-\mathrm{Pt}$ alloys near the composition $\mathrm{Fe}_{3} \mathrm{Pt}$, using the theory developed by Wechsler, Lieberman and Read and the crystallographic data recently accumulated. The calculated habit plane normals, directions of the shape strain, and relative twin widths of (112) transformation twins are not greatly different by the type of martensitic transformations. The magnitudes of total shape strain and lattice invariant shear are smaller for the thermoelastic type transformation. Particularly, the normal component of the total shape strain to the habit plane is much smaller for the thermoelastic type transformation roughly by one order of magnitude. The orientation relationship between the austenite and martensite lattices approaches the Nishiyama's as the transformation becomes thermoelastic. It is thus concluded that the distinct difference between the two types of martensitic transformations exists in the magnitude of the normal component of the total shape strain. This conclusion is also rationalized by a comparison of the thermoelastic Fe-Pt martensite with a non-thermoelastic Fe-Al-C martensite whose crystallographies are very similar to those of the former martensite.
\end{abstract}

(Received August 8, 1977)

\section{Introduction}

$\mathrm{Fe}-\mathrm{Pt}$ alloys near the composition $\mathrm{Fe}_{3} \mathrm{Pt}$ undergo two different types of martensitic transformations depending upon the degree of order of the austenite ${ }^{(1)}$. That is, when the austenite is in a disordered state, the martensitic transformation is non-thermoelastic as in many other ferrous alloys, whereas when the austenite is in a fully ordered state, it becomes thermoelastic as in many noble metal alloys with the $\beta$ phase. Therefore, the $\mathrm{Fe}-\mathrm{Pt}$ alloys are quite useful for a close examination of crystallographic differences between the two types of martensitic transformations. But, detailed crystallographic studies on the martensitic transformations in $\mathrm{Fe}-\mathrm{Pt}$ alloys had been limited to the non-thermoelastic one ${ }^{(2)(3)}$, and little information had been available for the thermoelastic one because of difficulties

* A part of this paper was originally read at the Annual Spring Meeting of the Japan Institute of Metals, April, 1977, Tokyo.

** The Institute of Scientific and Industrial Research, Osaka University, Yamadakami, Suita, Osaka 565, Japan. in the measurement of crystallographic properties over the subzero temperature range where the martensite is stable ${ }^{(1)}$. Recently, however, such difficulties have been overcome, and low temperature X-ray and electron diffraction and electron microscopy studies $^{(4)(5)}$ have indicated that the thermoelastic martensite has a BCT structure with a very large axial ratio, and that internal defects of the martensite are twins on a specific $\{112\}$ plane of the martensite, as in the non-thermoelastic martensite ${ }^{(3)}$. Thus, it has become possible to understand the whole crystallography of the thermoelastic martensitic transformation and to compare it with that of the non-thermoelastic one. The purpose of the present paper is to predict the crystallographic properties of the two types of martensitic transformations by using those available data, and to examine the origins causing such a remarkable change in the type of martensitic transformation.

The present calculations follow the phenomenological crystallographic theory developed by Wechsler, Lieberman and Read ${ }^{(6)}$, and have been carried out by an electronic computer using a program based on the one originally made by Otsuka ${ }^{(7)}$. The formulation

1977 Vol. 18 
of the well-defined theory will not be repeated here, and only input data for calculations and the results obtained will be described in the following.

\section{Input Data for the Calculations by the Phenomenological Crystallographic Theory}

Crystal structures of the austenite and martensite in $\mathrm{Fe}-\mathrm{Pt}$ alloys have been well established $^{(3)(8)}$, and they are shown in Fig. 1, in which a specific variant of the Bain correspondence between the two lattices adopted in the present calculations is also shown. When the austenite lattice is disordered, the martensite lattice has an ordinary $B C C$ structure. But, when the austenite is ordered to form the $\mathrm{Ll}_{2}$ type structure as shown in (a), the martensite produced in it becomes a base-centered tetragonal structure, the unit cell of which being four times as large as that of the disordered

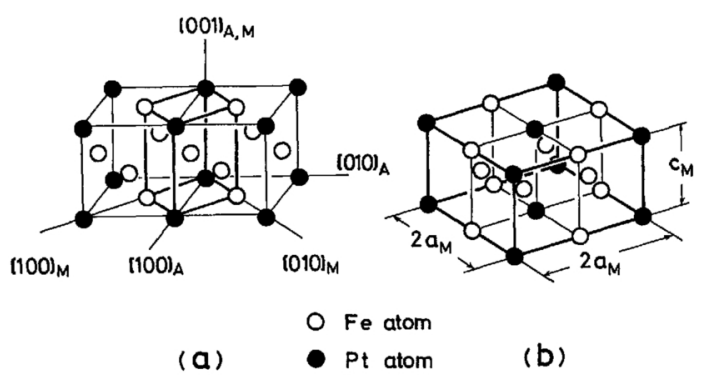

Fig. 1 Crystal structures of the austenite (a) and martensite (b) in ordered $\mathrm{Fe}_{3} \mathrm{Pt}$ alloy. (a) also shows a specific variant of the Bain correspondence between the two lattices adopted in the present calculation. Subscripts $A$ and $M$ refer to the austenite and martensite, respectively. martensite. At the same time, the one-fourth lattice corresponding to the unit cell of the disordered martensite forms a BCT lattice with a very large axial ratio, because of the ordered arrangement of two different kinds of atoms ${ }^{(4)}$. In the present paper, regardless of the disordered or the ordered structure of martensite, the ordinary cell size defined by the parameters $a_{M}$ and $c_{M}$ in (b) will be taken as that of the martensite lattice for simplicity. The lattice parameters of the austenite and martensite were previously determined for both the two types of martensitic transformations by means of low temperature X-ray diffraction ${ }^{(4)(5)}$, and those adopted for the present calculations are listed in Table 1, together with other related data.

The occurrence of twinnings on a specific \{112\} plane in the $\mathrm{Fe}-\mathrm{Pt}$ martensite was first verified for the non-thermoelastic martensite formed in a partially ordered $\mathrm{Fe}_{3} \mathrm{Pt}$ alloy ${ }^{(3)}$. That is, of the possible twelve $\{112\}$ twinning planes, only those with $l=2$ were observed to actually occur. As has been pointed out previously ${ }^{(3)}$, such a selection of specific $\{112\}$ twinning planes comes from a crystallographic requirement that otherwise the $\{112\}$ twinnings destroy the ordered structure inherited from the austenite. According to the lattice correspondence shown in Fig. 1, the specific $\{112\}$ twinning planes of martensite correspond to the $\{110\}$ austenite planes, which are mirror planes in the austenite lattice. This means that the specific $\{112\}$ twinnings are also compatible with the phenomenological requirement for transformation twinnings. The same situation

Table 1 Summary of experimental data on martensitic transformations in $\mathrm{Fe}-24 \mathrm{at} \% \mathrm{Pt}$ alloy.

\begin{tabular}{|c|c|c|c|}
\hline $\begin{array}{l}\text { Heat treatment } \\
\text { for ordering }\end{array}$ & As-quenched & $923 \mathrm{~K} \times 36 \mathrm{ks}$ & $923 \mathrm{~K} \times 360 \mathrm{ks}$ \\
\hline Degree of order & 0 & 0.7 & 0.8 \\
\hline $\mathbf{M}_{\mathbf{s}}$ temperature & $315 \mathrm{~K}^{*}$ & $198 \mathrm{~K}$ & $153 \mathrm{~K}$ \\
\hline Thermal hysteresis & $450 \mathrm{~K}^{*}$ & $35 \mathrm{~K}$ & $14 \mathrm{~K}$ \\
\hline $\begin{array}{l}\text { Lattice parameter } \\
\text { of austenite }\end{array}$ & $\begin{array}{l}0.3718 \mathrm{~nm} \\
\text { at R.T. }\end{array}$ & $\begin{array}{l}0.3734 \mathrm{~nm} \\
\text { at } 160 \mathrm{~K}\end{array}$ & $\begin{array}{l}0.3735 \mathrm{~nm} \\
\text { at } 137 \mathrm{~K}\end{array}$ \\
\hline $\begin{array}{l}\text { Lattice parameter } \\
\text { of martensite }\end{array}$ & $\begin{array}{l}0.2965 \mathrm{~nm} \\
\text { at R.T. }\end{array}$ & $\begin{array}{l}a=0.2870 \mathrm{~nm} \\
c=0.3152 \mathrm{~nm} \\
c / a=1.098 \\
\text { at } 77 \mathrm{~K}\end{array}$ & $\begin{array}{l}a=0.2857 \mathrm{~nm} \\
c=0.3176 \mathrm{~nm} \\
c / a=1.112 \\
\text { at } 77 \mathrm{~K}\end{array}$ \\
\hline
\end{tabular}

\footnotetext{
* These values were determined by Dunne and Wayman ${ }^{(1)}$
} 
has also been clarified to hold for the thermoelastic $\mathrm{Fe}-\mathrm{Pt}$ martensite ${ }^{(5)}$. In the present calculations, the (112) plane will be taken as the lattice invariant shear system, which corresponds to the (101) austenite plane due to the lattice correspondence in Fig. 1.

\section{Results}

Figure 2 shows the habit plane normals (n) and the directions of the total shape strain $(-d)$ calculated for the non-thermoelastic and thermoelastic martensites. The $n$ 's and $-d$ 's seem to move roughly towards the (011) and (011) poles, respectively, as the transformation becomes thermoelastic. But the angular differences between the $\boldsymbol{n}$ poles and between the $-\boldsymbol{d}$ poles for the two types of martensites are only about $6^{\circ}$ at the most. Therefore, it may be difficult to say that such differences are significant, because they are within the experimental scatter generally accepted in the determination of habit planes. Actually, Dunne and Wayman $^{(1)}$ have measured the habit plane normals of the two types of martensites by the

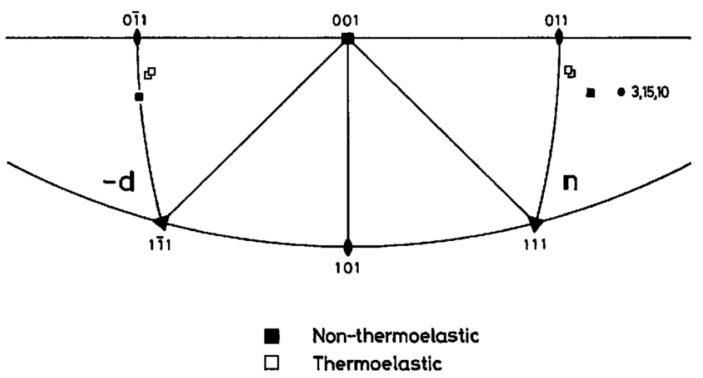

Fig. 2 Stereographic representation of habit plane normals (n) and directions of the total shape strain $(-d)$ calculated for the non-thermoelastic and thermoelastic martensites in $\mathrm{Fe}-24 \mathrm{at} \% \mathrm{Pt}$ alloy. method of two-surface analysis, and have reported that the difference between those for the two types is negligible.

The calculated relative twin width $x$ 's of (112) transformation twins are shown in Table 2 for the two types of martensites, together with numerical values of the habit plane mormals and the directions of the shape strain. They seem to have a tendency to decrease a little as the transformation becomes thermoelastic. But the $x$ 's recently determined by low temperature electron microscopy were roughly 0.3 and 0.4 for the non-thermoelastic and thermoelastic type martensites, respectively ${ }^{(5)}$. Therefore, the experimentally determined $x$ 's have an inverse tendency against the calculated ones. However, since the relative twin widths actually observed scatter considerably from martensite plate to plate ${ }^{(9)(10)}$, the inverse tendency is not considered to be very critical, and it may rather be said that such a slight change in the calculated $x$ 's is hardly detectable experimentally.

Table 3 shows the calculated orientation relationship between austenite and martensite lattices for the two types of martensitic transformations ${ }^{\dagger}$. The orientation relationship for

$\dagger$ When (101)[T01] in the austenite base, which corresponds to (112)[111] in the martensite base, is taken as the lattice invariant shear system, the so-called g-degeneracy does not hold, and therefore there are two crystallographically different orientation relationships ${ }^{(11)}$. The orientation relationship shown in Table 3 are solutions corresponding to smaller magnitudes of the lattice invariant shear, and other solutions corresponding to larger ones are disregarded for simplicity in the present paper.

Table 2 Numerical illustration of habit plane normals, directions of the shape strain and relative twin widths calculated for the non-thermoelastic and thermoelastic martensites of Fe-24at \%Pt alloy.

\begin{tabular}{lcrr}
\hline $\begin{array}{l}\text { Heat treatment } \\
\text { for ordering }\end{array}$ & As-quenched & $923 \mathrm{~K} \times 36 \mathrm{ks}$ & $923 \mathrm{~K} \times 360 \mathrm{ks}$ \\
\hline $\begin{array}{l}\text { Habit plane } \\
\text { normals }\end{array}$ & $\left(\begin{array}{l}0.17275 \\
0.76633 \\
0.61878\end{array}\right)$ & $\left(\begin{array}{l}0.11421 \\
0.73111 \\
0.67263\end{array}\right)$ & $\left(\begin{array}{l}0.10685 \\
0.72475 \\
0.68067\end{array}\right)$ \\
$\begin{array}{l}\text { Directions of } \\
\text { shape strain }\end{array}$ & {$\left[\begin{array}{r}-0.19483 \\
0.68923 \\
-0.69786\end{array}\right]$} \\
0.37148 & {$\left[\begin{array}{r}-0.12414 \\
0.67084 \\
-0.73114\end{array}\right]$} \\
0.34090 & {$\left[\begin{array}{r}-0.11559 \\
0.66668 \\
-0.73633\end{array}\right]$} \\
Relative twin \\
widths
\end{tabular}


Table 3 Calculated orientation relationship for the non-thermoelastic and thermoelastic martensitic transformations in $\mathrm{Fe}-24 \mathrm{at} \% \mathrm{Pt}$ alloy.

\begin{tabular}{lccc}
\hline $\begin{array}{l}\text { Heat treatment } \\
\text { for ordering }\end{array}$ & As-quenched & $\begin{array}{c}923 \mathrm{~K} \\
\times 36 \mathrm{ks}\end{array}$ & $\begin{array}{c}923 \mathrm{~K} \\
\times 360 \mathrm{ks}\end{array}$ \\
\hline$(111)_{\mathrm{A}} /(011)_{\mathrm{M}}$ & $0.65^{\circ}$ & $0.49^{\circ}$ & $0.48^{\circ}$ \\
{$[\overline{101}]_{\mathrm{A}} /[111]_{\mathrm{M}}$} & $3.95^{\circ}$ & $3.56^{\circ}$ & $3.48^{\circ}$ \\
{$[\overline{11} 2]_{\mathrm{A}} /[0 \mathrm{~T} 1]_{\mathrm{M}}$} & $1.35^{\circ}$ & $0.46^{\circ}$ & $0.38^{\circ}$ \\
\hline
\end{tabular}

Table 4 Calculated magnitudes of total shape strain and lattice invariant shear for the non-thermoelastic and thermoelastic martensites of $\mathrm{Fe}-24 \mathrm{at} \% \mathrm{Pt}$ alloy.

\begin{tabular}{lccc}
\hline $\begin{array}{l}\text { Heat treatment } \\
\text { for ordering }\end{array}$ & $\begin{array}{c}\text { As- } \\
\text { quenched }\end{array}$ & $\begin{array}{c}923 \mathrm{~K} \\
\times 36 \mathrm{ks}\end{array}$ & $\begin{array}{c}923 \mathrm{~K} \\
\times 360 \mathrm{ks}\end{array}$ \\
\hline $\begin{array}{l}\text { Magnitude of total } \\
\text { shape strain }\end{array}$ & 0.2284 & 0.1694 & 0.1619 \\
\hline $\begin{array}{l}\text { Normal } \\
\text { component }\end{array}$ & 0.0143 & -0.0026 & -0.0049 \\
\hline $\begin{array}{l}\text { Parallel } \\
\text { component }\end{array}$ & 0.2280 & 0.1694 & 0.1618 \\
\hline $\begin{array}{l}\text { Magnitude of lat- } \\
\text { tice invariant shear }\end{array}$ & 0.2477 & 0.1690 & 0.1586 \\
\hline \hline
\end{tabular}

the non-thermoelastic type transformation has been examined experimentally by both X-ray and electron diffraction methods, and it has been pointed out ${ }^{(2)(3)}$ that the agreement between theory and experiment is fairly good. Although data for the thermoelastic one have not been reported yet, the calculated orientation relationship becomes very close to the Nishiyama's as the transformation becomes thermoelastic. At present, however, it is not clear what physical meanings the Nishiyama's relation has for the thermoelastic martensitic transformation in ferrous alloys.

The magnitudes of the total shape strain calculated are listed in Table 4 together with those of the lattice invariant shear in the austenite base, the latter being calculated from the quantity of $2 x\left(2-\gamma^{2}\right) /\left(2+\gamma^{2}\right)$, where $x$ and $\gamma$ are the relative twin width of internal twins and the axial ratio of martensite lattice, respectively. According to the table, the magnitude of the total shape strain decreases as the transformation becomes thermoelastic. Particularly, resolving the total shape strain into two components normal and parallel to the habit plane, the decrease in the normal component is most remarkable. This remarkable decrease seems to distinguish the thermoelastic type from the non-thermoelastic one. The normal component is equal to the volume change during the transformation, and the volume change can also be obtained from a comparison of the martensite lattice parameter with the austenite one. The volume changes for the two types of martensitic transformations obtained from the comparison of lattice parameters previously determined at subzero temperatures ${ }^{(4)}$ are exactly the same as those listed in Table 4. As pointed out previously ${ }^{(4)}$, the volume change decreases remarkably with increasing the degree of order of the austenite, and its values for the thermoelastic type are of the same order as those for the typical thermoelastic transformations in some noble metal alloys with the $\beta$ phase. The component of the total shape strain parallel to the habit plane also decreases by an appreciable amount, but the amount of decrease is not so distinct as that of the normal component.

The magnitude of the lattice invariant shear becomes smaller as the transformation becomes thermoelastic, as known from its dependence on the axial ratio of martensite lattice, $\gamma$, as well as the relative twin width, $x$. But the decrease also seems not to be so effective for the change from the non-thermoelastic to the thermoelastic type.

After all, it is seen from the phenomenological calculations that distinct differences between the two types of martensitic transformations exist in the magnitude of the normal component of the total shape strain to the habit plane and also probably in the orientation relationship.

\section{Discussion}

In the last section, it has been shown that the decrease in the magnitude of the normal component of the total shape strain to the habit plane is particularly remarkable upon the change from the non-thermoelastic to the thermoelastic type. As stated above, the normal component of the total shape strain is 
nothing but the volume change associated with the transformation. One of the prerequisites for the thermoelastic nature of martensitic transformation has been considered to be that the coherency of interfaces between the austenite and martensite lattices is maintained over the whole process of transformation. The maintenance of the coherency may undoubtedly be realized only when the volume change is small $^{(12)}$. It is seen, therefore, that the remarkably small magnitude of normal component of the total shape strain is compatible with such a physical requirement for the thermoelastic nature of martensitic transformation, and that the most essential difference between the two types of martensitic transformations lies in the magnitude of the normal component of the total shape strain shown in the last section.

This is further supported by a comparison between the $\mathrm{Fe}-\mathrm{Pt}$ alloy and an $\mathrm{Fe}-\mathrm{Al}-\mathrm{C}$ alloy, because the martensitic transformation in $\mathrm{Fe}-\mathrm{Al}-\mathrm{C}$ alloy is non-thermoelastic, in spite of the fact that its crystallography is very similar to that of the thermoelastic one in the Fe-Pt alloy as follows: The austenite and the martensite in the $\mathrm{Fe}-\mathrm{Al}-\mathrm{C}$ alloy are also ordered in a similar manner to those in Fig. $1^{(13)(14)}$. As pointed out previously ${ }^{(15)}$, such an atomic orderings is quite important for the crystallographic reversibility in reverse transformation, which is another prerequisite for the thermoelastic nature of martensitic transformation. Thus, the $\mathrm{Fe}-\mathrm{Al}-\mathrm{C}$ alloy gives us even an impression that it may exhibit a thermoelastic type of martensitic transformation, although it has not been reported so far. In addition to the similarity in atomic ordering, the $\mathrm{Fe}-\mathrm{Al}-\mathrm{C}$ martensite has an extremely large axial ratio, which is a little larger than that of the thermoelastic $\mathrm{Fe}-\mathrm{Pt}$ martensite probably because of the high carbon content ${ }^{(16)(17)}$, and it is also completely twinned on a specific $\{112\}$ plane from one edge to another of martensite plates. Furthermore, interfaces between austenite and martensite lattices have well-defined planar shape $^{(14)}$ as those of Fe-Pt martensites. Therefore, the comparison between martensite crystallographies in those alloys should clearly
Table 5 Input data for the phenomenological calculation and other data for $\mathrm{Fe}-10 \mathrm{wt} \% \mathrm{Al}$ $1.5 \mathrm{wt} \% \mathrm{C}$ alloy together with those of $\mathrm{Fe}-24$ at $\% \mathrm{Pt}$ alloy.

\begin{tabular}{|c|c|c|}
\hline & $\mathrm{Fe}-24 \mathrm{at} \% \mathrm{Pt}$ & $\underset{(\text { wt } \%)}{\mathrm{Fe}-10 \mathrm{Al}-1.5 \mathrm{C}}$ \\
\hline $\begin{array}{l}\text { Heat treatment } \\
\text { for ordering }\end{array}$ & $923 \mathrm{~K} \times 360 \mathrm{ks}$ & As-quenched \\
\hline Degree of order & 0.8 & $>0$ \\
\hline $\mathbf{M}_{\mathbf{s}}$ temperature & $153 \mathrm{~K}$ & $>$ R.T. \\
\hline Thermal hysteresis & $14 \mathrm{~K}$ & - \\
\hline $\begin{array}{l}\text { Lattice parameter } \\
\text { of austenite }\end{array}$ & $\begin{array}{l}0.3735 \mathrm{~nm} \\
\text { at } 137 \mathrm{~K}\end{array}$ & $\begin{array}{l}0.367 \mathrm{~nm} \\
\text { at R.T. }\end{array}$ \\
\hline $\begin{array}{l}\text { Lattice parameter } \\
\text { of martensite }\end{array}$ & $\begin{array}{l}a=0.2857 \mathrm{~nm} \\
c=0.3176 \mathrm{~nm} \\
c / a=1.112 \\
\text { at } 77 \mathrm{~K}\end{array}$ & $\begin{array}{l}a=0.280 \mathrm{~nm} \\
c=0.319 \mathrm{~nm} \\
c / a=1.14 \\
\text { at R.T. }\end{array}$ \\
\hline
\end{tabular}

distinguish between the two types of martensitic transformations.

Table 5 shows the imput data available for the phenomenological calculations of the non-thermoelastic martensitic transformation in an $\mathrm{Fe}-10 \mathrm{wt} \% \mathrm{Al}-1.5 \mathrm{wt} \% \mathrm{C}$ alloy ${ }^{(17)}$, together with those for the typical thermoelastic one in the Fe-Pt alloy. The results are summarized in Fig. 3, and Tables 6 and 7. It is very interesting to note that there is no essential difference between the crystallographies of martensitic transformations in the two alloys except for the magnitude of the normal component of the total shape strain, that is, the volume change. The normal component of the total shape strain of the $\mathrm{Fe}-\mathrm{Al}-\mathrm{C}$ martensite is as large as that of the non-thermoelastic

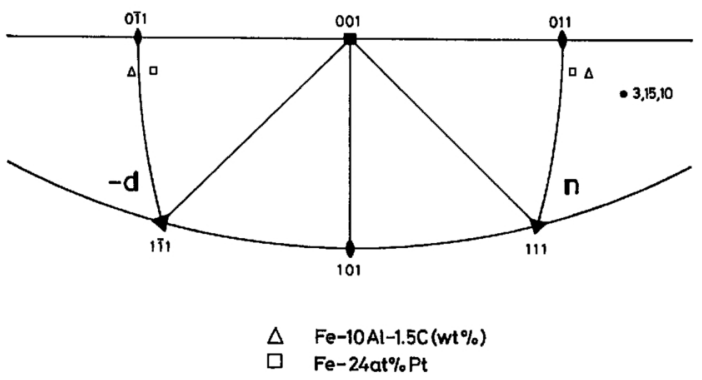

Fig. 3 Stereographic representation of a comparison between the habit plane normals and directions of the shape strain in non-thermoelastic $\mathrm{Fe}-$ $\mathrm{Al}-\mathrm{C}$ martensite and those in thermoelastic $\mathrm{Fe}-\mathrm{Pt}$ martensite. 
Table 6 Numerical illustration for a comparison between the habit plane normals, directions of total shape strain and relative twin widths in $\mathrm{Fe}-$ $10 \mathrm{wt} \% \mathrm{Al}-1.5 \mathrm{wt} \% \mathrm{C}$ martensite and those in $\mathrm{Fe}-$ 24 at $\%$ Pt alloy

\begin{tabular}{lcc}
\hline \hline & Fe-24at\%Pt & $\begin{array}{r}\text { Fe-10A1-1.5C } \\
(w t \%)\end{array}$ \\
\hline $\begin{array}{l}\text { Heat treatment } \\
\text { for ordering }\end{array}$ & $923 \mathrm{~K} \times 360 \mathrm{ks}$ & As-quenched \\
$\begin{array}{l}\text { Habit plane } \\
\text { normals }\end{array}$ & $\left(\begin{array}{l}0.10685 \\
0.72475 \\
0.68067\end{array}\right)$ & $\left(\begin{array}{l}0.11028 \\
0.76095 \\
0.63937\end{array}\right)$ \\
$\begin{array}{l}\text { Directions of } \\
\text { shape strain }\end{array}$ & $\left.\begin{array}{r}-0.11559 \\
0.66668 \\
-0.73633\end{array}\right]$ & {$\left[\begin{array}{r}-0.11898 \\
0.71410 \\
-0.68985\end{array}\right]$} \\
& 0.33625 & 0.36209 \\
$\begin{array}{l}\text { Relative twin } \\
\text { widths }\end{array}$ & & \\
\hline \hline
\end{tabular}

Table 7 Comparison between the orientation relationship and magnitudes of total shape strain and lattice invariant shear in $\mathrm{Fe}-10 \mathrm{wt} \% \mathrm{Al}-1.5 \mathrm{wt} \% \mathrm{C}$ and those in $\mathrm{Fe}-24 \mathrm{at} \% \mathrm{Pt}$ martensites.

\begin{tabular}{lcc}
\hline \hline & Fe-24at $\% \mathrm{Pt}$ & $\begin{array}{c}\mathrm{Fe}-10 \mathrm{Al}-1.5 \mathrm{C} \\
(\mathrm{wt} \%)\end{array}$ \\
\hline $\begin{array}{l}\text { Heat treatment } \\
\text { for ordering }\end{array}$ & $923 \mathrm{~K} \times 360 \mathrm{ks}$ & As-quenched \\
$(111)_{\mathrm{A}} /(011)_{\mathrm{M}}$ & $0.48^{\circ}$ & $0.21^{\circ}$ \\
{$[101]_{\mathrm{A}} /[111]_{\mathrm{M}}$} & $3.48^{\circ}$ & $2.81^{\circ}$ \\
{$[112]_{\mathrm{A}} /[011]_{\mathrm{M}}$} & $0.38^{\circ}$ & $0.60^{\circ}$ \\
$\begin{array}{l}\text { Magnitude of total } \\
\text { shape strain }\end{array}$ & 0.1619 & 0.1405 \\
$\begin{array}{l}\text { Normal } \\
\text { component }\end{array}$ & -0.0049 & 0.0125 \\
$\begin{array}{l}\text { Parallel } \\
\text { component }\end{array}$ & 0.1618 & 0.1400 \\
$\begin{array}{l}\text { Magnitude of lat- } \\
\text { tice invariant shear }\end{array}$ & 0.1586 & 0.1537 \\
\hline \hline
\end{tabular}

type of $\mathrm{Fe}-\mathrm{Pt}$ martensite. This is the reason why the martensitic transformation in the Fe-Al-C alloy cannot be thermoelastic in spite of a remarkable similarity to that in $\mathrm{Fe}-\mathrm{Pt}$ alloy, although there are still unknown factors in the $\mathrm{Fe}-\mathrm{Al}-\mathrm{C}$ martensite as to the behavior of carbon atoms during and/or after the transformation.

Recently, twin faults in thermoelastic $\mathrm{Fe}-\mathrm{Pt}$ martensites are observed to be very finely introduced, compared with those in nonthermoelastic ones ${ }^{(5)}$. Moreover, the width of twin faults in thin plate $\mathrm{Fe}-\mathrm{Ni}-\mathrm{C}$ martensites has been reported to decrease significantly with increasing carbon content ${ }^{(10)}$, the relative twin width $x$ being kept almost constant. According to Kajiwara and Owen ${ }^{(18)}$, large axial ratios of martensites result in a substantial reduction of the twin boundary energy and so, in those martensites, fine twins of high density are introduced in order for the strain at austenite-martensite interfaces to be elastically accomodated as much as possible. Unfortunately, the phenomenological theory only takes account of the relative twin width $x$ and not of the fineness of twin faults at all. But a subdivision of twin faults near the austenite-martensite interfaces have also been reported $^{(19)}$ in typical thermoelastic $\mathrm{Cu}-\mathrm{Al}-$ $\mathrm{Ni}$ martensite. Therefore, the introduction of fine twin faults of high density in $\mathrm{Fe}-\mathrm{Pt}$ martensites may also be essentially responsible for the change from the non-thermoelastic to the thermoelastic type.

\section{Acknowledgments}

The author wishes to express his sincere appreciation to Prof. K. Shimizu who suggested the present problem for his continued advice and guidance throughout this investigation. The present calculations were carried out by the Computer NEAC 2200, Model 700 at the Data Processing Center of Osaka University. Part of the present work was supported by the Grant-in-Aid for Fundamental Scientific Research (Shorei, 1976) from the Ministry of Education of Japan, and the support is greatly appreciated.

\section{REFERENCES}

(1) D. P. Dunne and C. M. Wayman: Met. Trans., 4 (1973), 137, 147.

(2) E. J. Efsic and C. M. Wayman: Trans. Met. Soc. AIME, 239 (1967), 873.

(3) T. Tadaki and K. Shimizu: Trans. JIM, 11 (1970), 44.

(4) T. Tadaki and K. Shimizu: Scripta Met., 9 (1975), 771.

(5) T. Tadaki, K. Katsuki and K. Shimizu: Proc. Internl. Symp. on New Aspect of Martensitic Transformation, Suppl. to Trans. JIM, Vol. 17, (1976), p. 187.

(6) M. S. Wechsler, D. S. Lieberman and T. A. Read: Trans. AIME, 197 (1953), 1503.

(7) K. Otsuka: Doctor Thesis, Tokyo University (1972). 
(8) A. Kussman and G. V. Rittberg: Z. Metallk., 41 (1950), 470.

(9) K. Otsuka and K. Shimizu: Trans. JIM, 15 (1974), 103.

(10) T. Maki and C. M. Wayman: Proc. Internl. Symp. on New Aspects on Martensitic Transformation, Suppl. to Trans. JIM, Vol. 17, (1976), p. 69.

(11) M. S. Wechsler: Acta Met., 7 (1959), 793.

(12) R. W. Cahn: Il Nuovo Cimento (Suppl.), 10 (1953), 350.

(13) Z. Nishiyama, K. Shimizu and H. Harada: Trans. JIM, 11 (1970), 152.
(14) T. Tadaki, K. Shimizu and T. Watanabe: Trans. JIM, 12 (1971), 386.

(15) C. M. Wayman and K. Shimizu: Met. Sci. J., 6 (1972), 175.

(16) Z. Nishiyama and M. Doi: J. Japan Inst. Metals, 8 (1944), 305.

(17) T. Tadaki and K. Shimizu: Trans. JIM, 16 (1975), 105.

(18) S. Kajiwara and W. S. Owen: Scripta Met., 11 (1977), 137.

(19) K. Otsuka, T. Takahashi and K. Shimizu: Met. Trans., 4 (1973), 2003. 